Esta revista forma parte del acervo de la Biblioteca Jurídica Virtual del Instituto de Investigaciones Jurídicas de la UNAM

\title{
UNA AGENDA HEMISFÉRICA \\ PARA LA DEFENSA \\ DE LA LIBERTAD DE EXPRESIÓN
}

\section{Víctor Hugo Hiram Magallanes Martínez}

En el Sistema Interamericano de Derechos Humanos (SIDH) existe una gran preocupación sobre cómo los Estados deben respetar, garantizar y proteger el derecho a la libertad de expresión; por ello, tanto la Comisión Interamericana de Derechos Humanos (en adelante CIDH o la Comisión Interamericana) como la Corte Interamericana de Derechos Humanos (en lo subsecuente CoIDH o Corte Interamericana) fijaron su posición respecto al tema desde diversos panoramas. En ese contexto, la Relatoría Especial para la Libertad de Expresión de la Comisión Interamericana de Derechos Humanos (en adelante Relatoría Especial o RELE), en busca de abordar las diferentes problemáticas que rodean a la libre expresión, ha tratado de interactuar con los Estados con la finalidad de que éstos adquieran un mayor compromiso y fijen ciertas políticas públicas que tiendan a privilegiar este derecho, de tal manera que se enfoca a observar determinados problemas en diversos contextos sociales y a crear una agenda encaminada a evitar malas prácticas por parte del poder público.

El trabajo de detectar problemas regionales y crear una agenda de defensa y prevención de violaciones al derecho a la libertad de expresión es loable si se tiene en mente y se plantea como meta la concreción de un sistema capaz de responder a todas las exigencias de la sociedad. Así, el trabajo realizado por la RELE que aquí se resume, y que se denomina "Una agenda hemisférica para la defensa de la libertad de expresión”, constituye una aportación significativa que llama a la colaboración de los Estados con los organismos pertenecientes al SIDH para crear un frente y, de esta manera, tratar de evitar graves atentados al ejercicio de este derecho.

\footnotetext{
* Licenciado en derecho; Juzgado Tercero de Distrito en el Estado de Morelos, biktor25@hotmail.com.
} 
Esta revista forma parte del acervo de la Biblioteca Jurídica Virtual del Instituto de Investigaciones Jurídicas de la UNAM

Para emprender una propuesta como la que realiza la Relatoría Especial, es necesario comenzar con un reconocimiento sobre las mejoras que se han concretado en los países de América Latina, es decir, primero hay que afirmar que sí ha habido avances en lo que se refiere a la libertad de expresión, pero también se debe reconocer que éstos han sido insuficientes.

En el texto del cual es objeto la presente reseña, la Relatoría Especial pone énfasis en que la libertad de expresión se encuentra consagrada en casi todas las leyes fundamentales, en las normas generales y programas de gobierno, lo cual genera una mejora en la región sobre el tratamiento de este derecho. También señala que, en la mayoría de los Estados, los me- canismos de censura directa son virtualmente inexistentes. Por mencionar - algunos ejemplos, expone que distintos Estados han derogado los delitos de desacato y difamación en sus diversas manifestaciones, mientras que otros tantos han incorporado o actualizado su legislación con el objetivo de garantizar el acceso a la información. Como consecuencia, se afirma que aunque la impunidad sigue siendo un problema grave, existen avances importantes en la materia.

El progreso en la región es evidente; sin embargo, también es indudable que, ante los avances en la materia, han surgido nuevas conductas o prácticas que violan el derecho a la libre expresión. Estas conductas han sido un foco de atención para la Relatoría Especial porque son novedosas. Entre las actuaciones que destaca la RELE se encuentran las formas de censura indirecta (la asignación discriminatoria de la publicidad oficial, la concentración de propiedad de los medios de comunicación, entre otros) y la autocensura.

Ahora bien, dentro del panorama general que reconoce la Relatoría Especial, se plantea que los progresos se originan en la consolidación o profundización de las democracias regionales; en la activa y protagónica participación de la sociedad civil en la defensa y promoción del derecho a la libertad de expresión en toda la región, y en el impulso que el SIDH le ha dado a este derecho en la última década.

Así, al referirse a la actividad que ha realizado la CoIDH, menciona que la jurisprudencia del sistema ha dejado en claro que todos los habitantes de la región tienen derecho a: 1) pensar por cuenta propia y expresar sus opiniones o ideas por cualquier medio y sin miedo a ser perseguidos, sancionados o estigmatizados por ello; 2) participar en el debate público en condiciones de equidad y a través de los medios que existen para fomentarlo y enriquecerlo; 3) conocer otras opiniones y visiones del mundo, y discutir las propias con quienes tienen posturas diversas o completamente 
Esta revista forma parte del acervo de la Biblioteca Jurídica Virtual del Instituto de Investigaciones Jurídicas de la UNAM

contrarias, y 4) acceder en detalle a la información relevante para ejercer el control político que hace posible una verdadera democracia deliberativa.

La RELE también expone cómo la Corte Interamericana ha emitido sentencias hito a lo largo de esta década, las cuales marcaron, cada una dentro de su ámbito específico, avances sobre el alcance de la libertad de expresión. Mientras que la CIDH, además de desarrollar el impulso derivado de sus atribuciones, adoptó la Declaración de Principios sobre Libertad de Expresión y publicó importantes informes de fondo que no sólo han puesto al continente americano a tono con los desarrollos jurídicos que se han dado a nivel mundial, sino que en, muchos casos, han impulsado dichos desarrollos.

Es evidente que la preocupación de contar con mejores prácticas en el ejercicio de la libertad de expresión es de todos, desde la sociedad civil (incluyendo a particulares, la academia, organizaciones no gubernamentales, etcétera) hasta los organismos que integran el sistema interamericano.

Una vez que la Relatoría Especial realiza esta especie de reconocimiento de progresos, insuficiencias y prácticas novedosas que violan la libre expresión, realiza una mención sobre los desarrollos jurisprudenciales más importantes en la materia, y parte de los siguientes puntos: 1) dimensión individual y colectiva del derecho a la libertad de expresión; 2) distintas funciones que cumple este derecho en las sociedades de expresión; 3) formas y discursos protegidos, especialmente por el derecho a la libre expresión, y los discursos no protegidos; 4) requisitos que deben demostrarse para justificar una limitación a este derecho y el tipo de limitaciones admisibles; 5) alcance del derecho de acceso a la información, y 6) otros desarrollos específicos y característicos del derecho a la libertad de expresión.

Los puntos descritos son muy importantes para comprender la posición y trabajo que han emprendido tanto la CIDH como la CoIDH en el desarrollo de una jurisprudencia sólida en la región, por ello resulta relevante precisar cada uno de esos puntos.

En torno al primero de ellos, la CIDH señala que la jurisprudencia interamericana ha caracterizado la libertad de pensamiento y de expresión como un derecho con dos dimensiones: una individual y otra colectiva. La primera consiste en el derecho de cada persona a expresar los propios pensamientos, ideas e informaciones. La segunda se refiere al derecho de la sociedad de procurar y recibir cualquier información (informaciones e ideas de toda índole), a conocer los pensamientos, ideas e informaciones ajenos, y a estar bien informada. En ese orden de ideas, se ha explicado que la libertad de expresión es un medio para el intercambio de informaciones. Por ello, se ha precisado que para el ciudadano común es tan 
Esta revista forma parte del acervo de la Biblioteca Jurídica Virtual del Instituto de Investigaciones Jurídicas de la UNAM

importante el conocimiento de la opinión ajena, o la información de que disponen otras personas, como el derecho a difundir las propias creencias o limitaciones.

Respecto a las funciones de la libertad de expresión, señala que cumplen con una triple función. En primer lugar, el derecho a la libertad de expresión desempeña la función de proteger el derecho individual de cada persona a pensar por sí misma y a compartir con otros informaciones y pensamientos propios y ajenos. Por otra parte, la CIDH y la CoIDH han subrayado que la importancia de la libertad de expresión, dentro del catálogo de los derechos humanos, se deriva también de su relación estructural con la democracia. En un tercer término, precisa que la libertad de expresión tiene una importante función instrumental, pues se trata de una herramienta clave para el ejercicio de los demás derechos fundamentales.

Sobre el tercer punto, la RELE establece que pueden identificarse como tipos de expresión protegidas por el artículo IV de la Declaración Americana, y el artículo 13 de la Convención Americana, la expresión oral, la escrita o impresa, la simbólica o artística, la difusión de ideas, pensamientos, opiniones, relatos, información u otras formas de expresión, la búsqueda, la obtención y la recepción de información, ideas, opiniones y otras formas de expresión, y la posesión de informaciones o materiales expresivos, impresos o en cualquier otra forma susceptible de tenencia, trasporte y distribución.

En relación con los requisitos que deben demostrarse para justificar una limitación al derecho a la libertad de expresión, se establece la exigencia de tres requisitos: 1) que sea definida en forma precisa y clara a través de una ley en sentido formal y material; 2) que persiga objetivos autorizados por la Convención, y 3) que sea necesaria en una sociedad democrática para el logro de los fines imperiosos que persigue, estrictamente a la finalidad perseguida e idónea para lograr tales objetivos.

En lo que atañe al derecho de acceso a la información, se establece que la CIDH y la Corte Interamericana consideran trascendente el derecho de acceso a la información al ser un componente vital de la libertad de expresión, pues comprende un derecho específico de las personas a acceder a tal información, y a la información sobre sí mismas o sobre sus bienes, contenida en bases de datos privadas, e imponiendo al Estado la obligación positiva de brindar a los ciudadanos acceso a la información.

De acuerdo con la Comisión Interamericana, la trascendencia del derecho de acceso a la información se explica por múltiples razones, entre las cuales resalta su carácter de herramienta crítica para la participación en democracia, su valor por considerarse como un medio para la autode- 
Esta revista forma parte del acervo de la Biblioteca Jurídica Virtual del Instituto de Investigaciones Jurídicas de la UNAM

terminación individual y colectiva, y su naturaleza de instrumento para el ejercicio de otros derechos humanos.

Finalmente, la Relatoría Especial establece que se ha prestado especial atención a ciertas manifestaciones específicas de protección convencional. Un ejemplo de ello es la interpretación estricta que se ha hecho sobre la prohibición de la censura en la Convención Americana sobre Derechos Humanos, que ha sido aplicada - tanto a las restricciones directas como a las restricciones indirectas de este derecho- en lo que se refiere a la actuación de autoridades y particulares, las cuales, pese al carácter sutil de los mecanismos por los cuales se implementan, surten el mismo efecto de inhibición, represión o silenciamiento de la libre expresión.

Una vez establecido el panorama general regional del derecho a la libre expresión, la RELE presenta su agenda en torno a los problemas persistentes y sus desafíos emergentes, destacando cinco puntos a tratar: 1) protección de periodistas y lucha contra la impunidad de los crímenes cometidos contra comunicadores en el ejercicio de su profesión; 2) necesidad de eliminar las normas que criminalizan la expresión y de impulsar la proporcionalidad de las sanciones ulteriores; 3) las mil caras de la censura; 4) los secretos de Estado, el derecho de acceso a la información y al habeas data, y 5) pluralismo, diversidad y libertad de expresión.

Los temas descritos son muy importantes para la Relatoría Especial en la medida que, para cada uno, establece una serie de observaciones y medidas que permitirán desarrollar mejores prácticas. Por ejemplo, en torno al primer tema, establece que, aunque no afecta a la mayoría de los países pertenecientes a la región, en la actualidad no parecen existir medidas suficientes y adecuadas para afrontar una exigencia de justicia con las víctimas y con la parte de la sociedad afectada por crímenes cometidos para acallar a periodistas y disidentes ideológicos. Al detectar este problema, la RELE se pronuncia al mencionar en que seguirá con la tarea de monitorear, denunciar y sensibilizar sobre este tema. Sin embargo, sugiere que es necesario impulsar los casos que se encuentran en el sistema interamericano, lo cual podría no sólo remover algunos obstáculos, sino también identificar y discutir las medidas que se han adoptado en materia de protección a los periodistas y la lucha contra la impunidad.

En otro tema, la Relatoría Especial propone que deben eliminarse normas que criminalizan la expresión, tales como las leyes de desacato y la legislación penal que protege la privacidad y el honor, o las normas que establecen la injuria religiosa, de símbolos o de instituciones. También propone eliminar la utilización de tipos penales de "terrorismo" o "traición a la patria", y desprenderse de los tipos penales orientados a criminalizar 
Esta revista forma parte del acervo de la Biblioteca Jurídica Virtual del Instituto de Investigaciones Jurídicas de la UNAM

la protesta social, pues ésta es una de las formas colectivas más eficaces de expresión.

En el tema que la RELE denominó como "las mil caras de la censura", menciona la idea de que no hay un solo argumento a favor de la censura que no hubiera sido ya derrotado. Ya no es una práctica común en la región la existencia de oficinas encargadas de censurar de manera directa. No obstante, han surgido nuevas prácticas de lo que se conoce como censura indirecta, la cual emerge como una obstrucción imperceptible, y se impone de manera silenciosa sin dar lugar a que sea investigada. Con base en lo anterior, existen cuatro formas de censura indirecta: la asignación arbitra- ria de recursos públicos, como publicidad oficial, frecuencias o subsidios;

- la utilización arbitraria de mecanismos de regulación y fiscalización; la creación de un ambiente de intimidación que inhibe la opinión disidente, y la autorización explícita o tácita de las barreras impuestas por particulares para impedir el libre flujo de ideas. Sobre estas formas de transgresión, propone, en síntesis, que deben existir marcos legales que conminen a los Estados a someterse a leyes precisas que impidan la discrecionalidad, en razón de que no hay leyes claras en las que se fijen criterios objetivos y razonables que atiendan a la necesidad de garantizar el pluralismo de ideas. Asimismo, señala que es necesario promover estándares para guiar las actuaciones del Estado para impedirle la utilización de su poder con el objetivo de amedrentar la circulación de ideas.

En relación con el tema del acceso a la información, la Relatoría Especial señala que su desafío es promover la promulgación de leyes de acceso en los Estados que aún no cuentan con este tipo de normas, pero además es importante realizar una revisión de las normas existentes en la actualidad, a fin de verificar si se apegan a los estándares internacionales en la materia. También resultaría pertinente establecer si el listado de excepciones que las leyes domésticas consagra, cumple con los requisitos de legalidad, finalidad legítima y necesidad.

Otro aspecto relevante detectado por la RELE es el referente a la definición o características de la información sensible que debe permanecer reservada, el derecho a acceder al dato primario en poder del Estado, y la obligación positiva de éste de producir o captar información relacionada con el cumplimiento de sus deberes. Por ello, resulta necesario impulsar los asuntos pendientes a través del sistema de casos individuales.

Por lo que se refiere a la figura del habeas data, la Relatoría Especial se ha fijado como reto promover la existencia de regulaciones que respeten los estándares interamericanos, de tal manera que sea garantizado para todos los habitantes de la región. 
Esta revista forma parte del acervo de la Biblioteca Jurídica Virtual del Instituto de Investigaciones Jurídicas de la UNAM

Finalmente, en torno al pluralismo, la diversidad y la libertad de expresión, la RELE se ha propuesto insistir en la urgente necesidad de aplicar leyes antimonopólicas para evitar la concentración de la propiedad y el control de los medios de comunicación y, en este sentido, también lograr que la asignación de frecuencias y licencias del espacio radioeléctrico respeten la obligación de inclusión que le impone a los Estados el marco jurídico interamericano para fomentar el pluralismo y la diversidad en el debate público.

Como ha sido expuesto en estas líneas, los temas abordados por la Relatoría Especial para la Libertad de Expresión son de suma importancia en la Región Latinoamericana, pues constituyen asuntos que en la actualidad representan problemas institucionales que impregnan el actual escenario social.

En esa medida, los aportes de la Relatoría Especial y la CoIDH constituyen un esfuerzo no sólo para evidenciar lo que se está realizando de manera inadecuada en la Región Latinoamericana, sino para proponer una serie de principios y estándares con el propósito de tener una mayor incidencia en el fortalecimiento de los procesos de la sociedad. Con la presentación de sus desafíos, la RELE no sólo se enfoca en su propia actuación, sino que envía un mensaje a los Estados para adecuar sus políticas para garantizar un mejor ejercicio de los derechos humanos.

\section{BibLIOGRAFÍA DEL LIBRO RESEÑADO}

Comisión Interamericana de Derechos Humanos, 2010, Una agenda hemisférica para la defensa de la libertad de expresión, Organización de Estados Americanos. 